\title{
NUEVAS APROXIMACIONES AL CONCEPTO DE SOCIEDAD CIVIL. \\ De la sociedad civil a la sociedad de control
}

\author{
Por: Oscar Useche Aldana
}

\section{Resumen}

El autor hace un rastreo de los orígenes de la categoría "sociedad civil" en el pensamiento de la modernidad y de la profunda crisis que atraviesa en la actualidad. Se plantea que las sociedades de hoy se enfrentan a espacios políticos y sociales que han transformado lo que se ha conocido como el universo de lo público. Ya esto había sido analizado por Foucault, quien dibujó una sociedad civil basada en la disciplina y productora de una intrincada trama de redes de normalización. La pregunta que se desarrolla en el artículo es si las instituciones de socialización están en medio de una transición que las integra a proyectos de sociedades de control más que a redescubrir su potencialidad democrática.

\footnotetext{
Oscar Useche Aldana es economista, Magíster en Investigación Social Interdisciplinaria , con estudios de Doctorado en Paz, Conflictos y Democracia. Director del Centro de Estudios e Investigaciones Humanas y Sociales (CEIHS) de UNIMINUTO. Director de la
} Revista Polisemia.

\begin{abstract}
The author traces the origins of "The Civil Society", in the notion of modernity and of the profound crisis that is currently going through. It is suggested that today's society faces political and social areas that have been transformed as a universal space, as it is known today. Foucault had already analyzed this. He had pictured a civil society based on discipline and producer of intricate normalization schemes. The question that is developed in this article is whether the socialization of institutions is currently in a transition that integrates them to projects of social control or if it's beyond the rediscovering of its democratic potential.
\end{abstract}


En las últimas décadas se vive un nuevo auge del uso de la categoría "sociedad civil" y de su invocación para la acción. En Europa la sociedad civil se convirtió en elemento clave del final de la guerra fría, especialmente en el tránsito de los países de Europa oriental al mundo pleno del mercado. En América Latina la fatiga de los partidos políticos y de sus formas clientelares de actuación y el desgaste de las formas tradicionales de representación, han hecho volver la mirada sobre el concepto intentando encontrar allí la fuente de las alternativas.

Se trata de una categoría típicamente moderna asociada a la del ciudadano así como a una visión particular del papel del EstadoNación y de la construcción del mundo de lo público. Las actuales sociedades se enfrentan a espacios políticos y sociales diferentes que erosionan lo que se ha conocido como el universo de lo político.

El problema es que estas nociones básicas, que fueron tan decisivas para la constitución del orden de lo moderno, atraviesan una profunda crisis que se hace patente, a pesar de los fulgores pasajeros con lo cuales se tratan de remozar esporádicamente sujetos colectivos abstractos como la llamada sociedad civil. La importancia de ella deriva del hecho de haber sido concebida como un sistema de relaciones para la mediación que legítima y racionaliza el encuentro de los intereses individuales y los colectivos y da luz el escenario de lo público. La pregunta es si las instituciones sociales necesarias para la construcción y el funcionamiento de la sociedad civil todavía están presentes en las formaciones sociales contemporáneas.

\section{Rastreando el origen de la Sociedad Civil.}

Diversos autores han ubicado en los finales del siglo XVIII el surgimiento de idea de una esfera de la sociedad distinta del estado y con formas y principios propios. Aquí se destaca la influencia del pensamiento social británico plasmado en los escritos de Locke, de Smith y de otros muy influidos por la nueva ciencia de la economía política ${ }^{1}$.

No obstante es Hegel quien dibuja los contornos de la sociedad civil determinada por las fuerzas económicas, especialmente por una concepción del trabajo y por la búsqueda de la autorrealización individual de las personas. Se trataría de un dominio social en donde los ciudadanos se agrupan de acuerdo a sus propios intereses y deseos, un plano paralelo, que ejerce una función de intermediación entre los individuos en su estado natural en busca de la constitución de lo común, en ese sentido solidario con el Estado, pero a la vez separado de él. Esta idea recogía los cambios que ya entonces se evidenciaban en el capitalismo en su fase industrial, el surgimiento de la burguesía como clase y la creciente demanda de libertad expresada que habían traído consigo las revoluciones americana y

\footnotetext{
${ }^{1} \mathrm{Al}$ respecto, véase el recorrido histórico sobre el concepto hecho por Luís Jorge Garay en "Ciudadania, lo Público, Democracia. Notas y Textos”. Bogotá, 2000.
} 
francesa. La sociedad civil es constituida entonces como una infraestructura institucional de primer orden para las mediaciones indispensables a la política y al mercado.

En la filosofía política, el concepto de sociedad civil es conectado fundamentalmente a la noción moderna de trabajo. Tal como señala Michael Hardt, esta conexión fue hecha evidente por el propio Hegel. ${ }^{2}$ El pensador alemán se concentró ante todo no en el contraste entre sociedad de naturaleza y sociedad civil, sino entre sociedad civil y sociedad política, o bien entre sociedad civil y Estado. Hasta entonces el predominio de análisis de tipo Hobbesiano proponía como única alternativa al estado de naturaleza, en donde primaba el estado de guerra entre los individuos, la soberanía del leviatán estatal.

El desarrollo del capitalismo en Europa posibilitó análisis más complejos. Según Hegel, por las necesidades, el trabajo, los cambios y la búsqueda del propio interés particular, los "átomos no organizados de la sociedad civil" van organizándose hacia lo universal -no justo a través de la misteriosa acción de la mano invisible de Adam Smith, sino por las instituciones competitivas de la producción y la circulación capitalista-. El estado de naturaleza como reino de las necesidades y la búsqueda del propio interés, no tienen para Hegel una relación directa con el Estado

${ }^{2}$ En este artículo se hace alusión al texto de Hardt: "La desaparición de la sociedad civil" en Revista Nova et Vetera No. 49. Instituto de Derechos Humanos. Esap. Bogotá. 2002 .Y al escrito de A. Negri "Guias". Paidós. Barcelona 2004. político sino que tiene que pasar por encontrar una mediación con la sociedad civil antes de convertirse en política. La sociedad civil, subraya Hegel, comparte con la sociedad de naturaleza el hecho de ser el reino de las necesidades y del interés particular pero la sociedad civil también es "la esfera del emparentamiento -la esfera de la educación». En otras palabras, la sociedad civil asume el sistema humano natural de necesidades e intereses privados y pone en relación unos con otros a través de las instituciones sociales capitalistas de la producción y el mercado y así, sobre la base de la mediación y de la subsunción de lo particular pone las bases sobre las que el Estado puede realizar el interés universal de la sociedad. (Hardt, 2002).

El egoísmo de la sociedad de naturaleza, enunciado por Hobbes es superado por el trabajo que, al tiempo que busca satisfacer las necesidades y deseos humanos, genera cooperación. Y es en ese campo en donde surgen las organizaciones sindicales y las mutuales del trabajo, una de las organizaciones civiles fundadoras de la sociedad civil moderna. Aquí cabría una función pedagógica del trabajo - la transformación hacia lo universal, la organización y agrupamiento de los individuos- tal como lo concibe Hegel. Pero, como lo remarca Hardt (2002), la sociedad civil consiste no solamente en las corporaciones del trabajo, sino en todas las instituciones de la sociedad capitalista que organizan el trabajo abstracto. El paso del trabajo concreto al trabajo abstracto es una operación de captura, de enajenación que se 
realiza en esta fase del capitalismo (K. Marx, El Capital) y en el cual es vital la mediación de las instituciones de la sociedad civil. Para Hegel, los objetivos del movimiento social son adquiridos en la media en que se les reconoce por el Estado y en que éste los considera suyos. Esta es la realización de la idea ética hegeliana.

La Sociedad Civil: ¿Constructora de Democracia o Reproductora de Despotismos?

A lo largo de la historia de las luchas sociales de la modernidad, varios sectores han concebido la sociedad civil como un espacio potencial productor de democracia. Otros han analizado sus funciones como red privilegiada de circulación de las enunciaciones del poder de dominación y de resonancia del Estado.

Antonio Gramsci puso en uso las metáforas construidas en la lucha obrera y la utopía marxista para aportar el concepto de hegemonía política y cultural, fundada precisamente en las fuerzas de la democracia que habitan los espacios de la sociedad civil. La lucha por la hegemonía es, a su manera de ver, un combate en la esfera de la cultura política desde donde la sociedad puede jugar a la estrategia de la búsqueda de nuevos consensos y vaciar al Estado de este privilegio. En últimas su proyecto se inscribe en la utopía de Marx de la disolución de los Estados, que para Gramsci no es otra cosa que la reabsorción de la sociedad política por la sociedad civil
La lucha por el poder se transforma entonces en una guerra de posiciones en donde los intelectuales orgánicos, que asumirian el papel de formadores, promoverían el autogobierno de las organizaciones, fortalecerían el poder de los múltiples espacios de la sociedad civil y vaciarían de su poder coercitivo al Estado y reabsorberían sus funciones construyendo así una democracia radical.

En la perspectiva de otros investigadores, sin embargo, aquella intermediación institucional que define la relación entre sociedad civil y Estado es mostrada en una función proyectada hacia objetivos de dominación y despotismo, muy lejanos de la democracia. El mecanismo que produce la sociedad civil es, desde esta mirada, la mistificación de las formas de representación del poder, por las cuales antes que hacer posible una influencia de la sociedad sobre el poder central, éste despliega su capacidad de cooptar las potencias sociales e incluso de producir, sobre ellas, nuevas relaciones de dominación.

En esta dimensión, las instituciones de socialización en las cuales se materializa la sociedad civil devienen estructuras de encierro y disciplinamiento de las fuerzas sociales codificando sus técnicas y estrategias de gobierno y convirtiéndolas en espacios de repercusión del poder de centro. Así, la familia nuclear, la escuela moderna, la iglesia, el hospital, el manicomio, el cuartel y demás instituciones se constituyen en el terreno por excelencia para la producción de sujetos normalizados y para el mantenimiento de la 
disciplina del sistema de producción económica y la reproducción social. Es lo que Michel Foucault llama la sociedad disciplinar.

La preocupación por el encauzamiento de la conducta se manifiesta en los esfuerzos por reglamentaciones estrictas, de tal manera que el cuerpo jurídico global es complementado por multiplicidad de reglamentos específicos, de manuales para la vida cotidiana, de recetas para el mantenimiento de las buenas costumbres, que van constituyendo un aparato semiótico que busca hacer cuerpos dóciles a través de la disciplina.

Todos las instituciones de la sociedad civil y Ios equipamientos colectivos, los destinados a la pedagogía, los conventos, los cuarteles, difunden las recetas y adiestran en los códigos de comportamientos.

Sujetar los cuerpos, adscribirlos a sistemas de control por medio de infinidad de procesos minuciosos, con frecuencias de repetición que crean rutinas y fomentan hábitos, desbrozan el camino de la obediencia y actúan sobre los colectivos, descomponiéndolos, jerarquizándolos, convirtiéndolos en órganos del cuerpo societal el cual está preparado para sancionar moral o físicamente a los renuentes.

Y en el claroscuro, como una presencia disuasiva, la cárcel, produciendo signos comprensibles a todos, hablándole a todos los culpables posibles de la conveniencia de controlar sus apetitos y de preferir la virtud al delito.
Toda esta parafernalia disciplinaria es completamente funcional a las leyes del mercado, son el complemento de la disciplina del mercado. Todo ciudadano sensato y de buenas costumbres entiende que los límites de su deseo de consumo están marcados por su capacidad de pago. Allí está marcada la tolerancia del sistema para con su ambición.

Se promueven pactos sociales en los cuales los individuos se comprometan a respetar estos límites, a sustituir la agresividad física en la búsqueda de la satisfacción de sus deseos, a respetar la vida de los demás y las reglas del juego de la sociabilidad. La ley y la violencia legítima, ora física, ora simbólica, son el referente para los miembros de la sociedad civil, cuya categoría de ciudadanos sólo es reconocida a través de su propio reconocimiento de estos mecanismos y de su sometimiento a cualquiera de los espacios de socialidad que habilitan las instituciones de la sociedad civil.

A cambio, el sujeto ciudadano podrá participar en el mercado, en la búsqueda de la satisfacción de un deseo: poseer bienes. Para ello se hace indispensable la igualdad, cosa que en este caso significa, compartir costumbres semejantes para competir en el mercado.

La regulación de lo cotidiano es entonces elemento de gran significación en las sociedades disciplinares. La disciplina le asigna lugar de consideración política a los detalles de la convivencia, ocupándose de la descripción, de los procedimientos y de las técnicas meticulosas del comportamiento humano. 
Con ello no sólo contribuye al control de las conductas del ciudadano, sino que define las líneas de perspectiva para la objetivación del "hombre de bien", del "ciudadano decente", diferenciándolo de aquel que no se atiene a la norma, del no-conviviente. Se constituye entonces en un mecanismo de exclusión, que así mismo objetiviza al "anormal", al "Sospechoso".

Como bien señala Hardt (202) Foucault critica las instituciones de la sociedad civil con la misma intensidad que Hegel las celebra. La dialéctica social funciona de manera tal que las fuerzas sociales antagonistas son subsumidas dentro de la síntesis preexistente y unitaria del Estado.

En esta escena, las búsquedas de construcción de lo público, de lo colectivo, que han tomado como suyas las luchas minoritarias que se esfuerzan en hallar espacios para su diferencia y su creatividad, son encasilladas desde los agenciamientos estatales y mediáticos, en meras demandas de poder adquisitivo y de participación en el sistema; es decir son cooptadas como demandas de "inclusión".

Son numerosos los ejemplos acerca de cómo la potencia vital de los movimientos sociales que lucharon por la autonomía de grupos sociales minoritarios, ha sido uno de los motores de transformaciones en las formas de reproducción del capital. Así también puede interpretarse la manera como fue asimilada la resistencia obrera de las prime- ras décadas del siglo XX para convertirla en base nutricia sobre la cual se reactivaron los mercados y se amplió el consumo durante las épocas de las crisis de demanda ${ }^{3}$.

Una vez más, detrás de las fuerzas de la vida que aparecen en los límites, que se la juegan en el margen para impedir que se detenga la creación del mundo de lo social, cabalgan siempre las fuerzas de poderes aplastantes, que intentan convertir la diferencia en homologación e indiferenciación, siempre tratando de ampliar sus bases. $Y$ ello no es para nada sinónimo de democracia sino más bien un laboratorio desde donde se pueden percibir las señales que provienen de la sociedad para plantear nuevas fórmulas de cooptación, que permitan plegar y hacer ajustes para el mantenimiento del orden existente.

Es en esta dirección que Foucault argumenta que el poder no radica en un solo lugar y se aparta de la idea de que ese lugar es únicamente el del Estado, concebido como aparato de fuerza que monopoliza el poder. El poder es reticular, circula y, de cierta manera se encuentra por todas partes, viene de cada intersticio; no hay lugar en donde no se configuren unas relaciones de poder y en ese sentido no cabría una separación teórica entre sociedad política y sociedad civil.

“En la sociedad disciplinal y gobernizada, las líneas del poder se extienden por todo el

3 "Las irracionalidades de la organización capitalista de la producción han sido corregidas, más o menos, mediante la resistencia permanente de los trabajadores". C. Castoriadis.. "El descalabro de Occidente". Revista Archipiélago No.9. Barcelona. 
espacio social a través de los canales creados por las instituciones de la sociedad civil. El ejercicio del poder se organiza mediante aparatos, que son al mismo tiempo ideológicos, institucionales y corporales". (Hardt 2002).

Educación significa disciplina. Precisamente, Foucault reformula el criterio "educativo" de la sociedad civil en términos de producción: el poder actúa no solamente amaestrando y ordenando los factores del territorio social, sino produciéndolos efectivamente -produciendo deseos, necesidades, individuos, identidad, etc. La sociedad disciplinal puede ser caracterizada como sociedad civil desde una perspectiva diferente, vista desde un nivel de abajo, desde la microfísica de sus relaciones de poder.

Así, mientras Gramsci subraya al potencial democrático de las instituciones de la sociedad civil, Foucault desvela que la sociedad civil es una sociedad basada en la disciplina y que la educación que ella ofrece es en realidad una trama de normalización ${ }^{4}$.

\footnotetext{
${ }^{4}$ Otras concepciones también aportan al debate sobre la "sociedad civil" hoy. Desde la definición negativa de Bobbio: "Se entiende por sociedad civil la esfera de las relaciones que no está regulada por el estado, entendido restrictivamente... La sociedad civil es donde se ejerce la hegemonia, diferente del dominio, liberada de la sociedad política", (2001). Pasando por la de Habermas, en el marco de la teoría discursiva de la democracia que observa un redescubrimiento del concepto lejos del marco de las teoría liberales soportadas en Hegel y a la concepción marxista. "Constituye el sustrato organizativo de ese público general de ciudadanos que surge, por así decir, de la esfera privada y que busca interpretaciones públicas para sus intereses sociales y para sus experiencias, ejerciendo así influencia sobre la formación institucionalizada de la opinión y la voluntad políticas"
}

\section{De la sociedad civil disciplinar a la sociedad de control.}

La decadencia del paradigma de la sociedad civil está relacionada con el paso de una nueva configuración de las relaciones sociales hacia nuevas condiciones del dominio en la sociedad contemporánea. Con eso no se quiere decir que las formas y las estructuras del cambio social, de la participación y del dominio que han sido identificadas por el concepto de la sociedad civil hayan dejado completamente de existir sino que ellas han sido removidas por la posición preeminente de una nueva configuración de aparatos, dispositivos y estructuras.

Las sociedades disciplínales están caracterizadas por estructuras cerradas o instituciones que funcionan de esqueleto y espina dorsal de la sociedad civil.

Estas instituciones totales definen las puertas estrechas del espacio social. La trama coordinada formada por las instituciones de la sociedad civil se divide dentro del espacio social en una red estructurada como los túneles de un topo (Negri, 2004)

Las principales instituciones cerradas de las sociedades disciplinares muestran una crisis de desintegración. La más resistente y adaptativa hasta ahora, la familia nuclear, se fractura sin remedio.

El nuevo antagonismo hombre - mujer, desatado por la vinculación de la mujer a la 
producción y por los resultados liberadores de la revolución sexual; el debilitamiento de la autoridad patriarcal, el trabajo infantil, la resistencia a la normalización por parte de los jóvenes, etc. le hacen perder la fuerza de centro de la reproducción de las relaciones sociales.

La fábrica desaparece víctima de la reestructuración del capitalismo. Las grandes concentraciones obreras bajo un mismo techo, sujetas a las cadenas de producción y las técnicas de administración de tradición taylorista (control de tiempos y movimientos) son reemplazadas por nuevos cortes de los flujos del capital y por el surgimiento de nuevos equipamientos productivos. Los muros de las fábricas se resquebrajan y con ellos el sentido y el poder del viejo sindicalismo ${ }^{5}$.

Qué decir de la escuela; del cuartel - contra el que empieza a abrirse paso la objeción al șervicio militar obligatorio- ${ }^{6}$; o de la cárcel que hoy muestra a sus presos en rebelión para decir que ese tipo de encierro se agotó. Todo el interior, el "adentro" de la organización social

\footnotetext{
${ }^{5}$ "Los sistemas de encierro son moldes de vaciados distintos... Esto lo constatamos particularmente en lo que respecta a los salarios. La fábrica era un cuerpo que llevaba sus fuerzas internas a un punto de equilibrio: el más alto posible para la producción, el más bajo posible para los salarios...La fábrica transformaba los individuos en cuerpos para una doble ventaja, de un lado de los patrones, que vigilaban cada elemento de la masa y de otro lado de los sindicatos, que movilizaban una masa de resistencia». G. Deleuze. "Las sociedades de control». Revista Encuentros. No. 3. Buenos Aires 1992.

${ }^{6}$ Benjamin señalaba que la crítica al militarismo significaba una crítica de la violencia en general ya que : «la doble función de la violencia es característica del militarismo, que sólo puede constituirse como tal, con el advenimiento del servicio militar obligatorio. El militarismo es el impulso de utilizar de forma generalizada la violencia como medio para los fines de Estado...Refleja una utilización de la violencia como medio para fines de derecho, ya que la sumisión de los ciudadanos a las leyes- dado el caso la obediencia a la ley del servicio militar obligatorio- es un fin de derecho.» W. Benjamin. "Para una crítica de la violencia y otros ensayos" Taurus. Madris 1991.
}

estalla para ceder su lugar a nuevas formas de relacionamiento y control social.

En la sociedad urbana se va dibujando el nuevo monstruo deleuziano: la "sociedad de control". Las nuevas velocidades, los nuevos ritmos introducidos por la tecnología y la ciencia se traducen en flujos de todo tipo que rompen los límites de las estructuras cerradas y que, igualmente, se manifiestan en formas de aceleración inusitada en los mecanismos de control en espacios abiertos.

"La cultura tecnológica no ha hecho mas que perfeccionar la apropiación de los elementos motrices, y acrecienta incesantemente nuestra dependencia de los sistemas que regulan el sentido de la apropiación (contadores de velocidad, tableros de mando, teleorientación...). Creadora de itinerarios de dirección, aplica a la tierra y a la naturaleza (a la naturaleza humana) la fórmula de Bacon: Nada es más vasto que las cosas vacías... y finalmente crea el vacío y el desierto por que solo la nada es continua y, por ello conductoran. ${ }^{7}$

\footnotetext{
${ }^{7}$ Paul Virilio. «Estética de la desaparición». Anagrama. Barcelona, 1988. Este urbanista francés ha desarrollado una teoría de la velocidad como factor esencial en los cambios en el modo de producción y dominación de la subjetividad. En la obra citada agrega : «! No tenéis cuerpo, sois cuerpo!» clamaba ayer Wilhelm Reich; a lo que el poder y sus técnicas responden hoy «No tenéis velocidad, sois velocidad." Ya en mi libro "Vitesse et Politique», mostré de qué modo la modulación y la manipulación de las velocidades vectoriales (la policia logística) habian sido, en los diversos conflictos militares y revolucionarios, los elementos más eficaces para lograr la cohesión de las masas en Europa y Estados Unidos. Pero, al mismo tiempo señalé que el fin buscado por el poder no era solo la invasión u ocupación de los territorios sino, sobre todo, la creación de una suerte de resumen del mundo obtenido mediante la ubicuidad, la instantaneidad de la presencia militar, es decir un puro fenómeno de velocidad, un fenómeno en marcha hacia la realización de su esencia absoluta»
} 
completamente con las modulaciones del control. La relación entre sociedad y Estado no se desarrolla más a través de la mediación y la organización de las instituciones por la disciplina y el dominio. En cambio, la relación configura directamente un Estado en movimiento por la circularidad continua de la producción social.

Las instituciones no ocupan una posición primaria como inicio de las relaciones sociales; ellas representan el ensamblaje de las estrategias del poder. Lo que sustenta las muchas instituciones es el esquema: la máquina estratégica anónima y abstracta, el esquema no definido y no-estratificado de las relaciones de poder. El diagrama transciende, o mejor implica, los varios ensamblajes institucionales.

No los pasos estructurados del topo, insiste Deleuze, sino las infinitas ondulaciones de la serpiente, son las que caracterizan el espacio liso de las sociedades del control

El espacio metafórico de las sociedades de control es mejor definido por los continuos desplazamientos de las arenas del desierto, donde las posiciones son continuamente barridas; o mejor, por las superficies lisas del cyberspacio, con sus indefinidamente programables flujos de códigos e informaciones.

Estas metáforas sugieren un importante cambio señalado por el diagrama de la sociedad de control. El esquema del control, en cambio, no es orientado tanto hacia la posi- ción o la identidad como hacia la movilidad y el anonimato. Las sociedades de control preservan el carácter anónimo común a todos los esquemas y rechazan la particularización que anteriormente acompañó el paso del esquema en ensamblajes e instituciones molares. Controles complejos sobre los flujos informativos, empleo extensivo de los sondeos y técnicas de monitoreo y empleo social innovador de los medios de comunicación, todo ello conquista la posición dominante en el ejercicio del poder

El control funciona sobre el plan de las imágenes de la sociedad, el anonimato y la “cualquieridad”. (Agamben, 1997). Afirmar la decadencia de la sociedad civil no significa que todos los mecanismos del mando y de la organización que caracterizaron la sociedad civil no existen, igualmente, admitir el paso de las sociedades disciplinares a las de control no significa que los dispositivos disciplínales y la correlativa potencialidad de resistencia hayan desaparecido. Los mecanismos disciplinares quedan, tal como los elementos de la soberanía, en los regímenes de control.

En este paso las instituciones democráticas y/o disciplinares de la sociedad civil, los canales de la mediación social como forma particular de la organización del trabajo social, se han debilitado y han sido removidos del centro de la escena. ¡No el Estado, sino la sociedad civil ha vivido un proceso de deterioro! En otras palabras, aunque alguien pudiera considerar la sociedad civil política- 
Se impone el control continuo y se reorganiza el poder político, centrado ahora en las redes de comunicación, en la vigilancia automática y la respuesta inmediata a cualquier amenaza contra el orden. La ciudad (polis) se va transformando en la ciudad policiva. La ciudad punitiva tiende a adquirir la forma de la ciudad controladora.

La disciplina impuesta desde cada uno de los centros de encierro, que contaba con normas específicas para cada uno, va siendo reemplazada por la modulación de las conciencias que reclama el autocontrol en todos los espacios, a través de la utilización masiva de nuevos lenguajes numéricos, cibernéticos.

Los códigos específicos para cada compartimiento social, desde donde se disciplinaba al ciudadano, dejan su lugar a un mar de información que se proporciona a todos los individuos, desalentando las sensaciones propias y confirmando cotidianamente por medio de una lluvia de imágenes cuál es el mundo que lo rodea: el vacío, la nada.

El punto de partida de esta transformación es el vuelco que ha tomado la producción. La descentración y deslocalización de la fábrica, posibilitada por la revolución de las comunicaciones y el cambio de énfasis hacia la producción de servicios, soportan una completa dispersión de la actividad productiva.

La ciudad, el país, la región hacen parte de una gran empresa global que integra a su lógica los antiguos centros de producción y reproducción del capital. "La familia, la escuela, el ejército, la fábrica no son ya mas centros analógicos diferenciados que convergen en un propietario, Estado o potencia privada, sino las figuras cifradas, deformables y transformables de una misma empresa que funciona únicamente con gerentes". ${ }^{8}$

Las modernas técnicas de la administración (control de calidad, reingeniería, etc.) perfeccionan los métodos de incorporación del conocimiento del productor directo y del consumidor a la gran inteligencia artificial del capitalismo y permiten ajustes rápidos en la tecnología y la escala de la producción. Al trabajador se le asigna así también un papel en la gestión de la empresa.

Se puede interpretar la crisis de la fábrica, de la familia, de la Iglesia y de otras estructuras sociales como la progresiva demolición de muchos muros sociales cuyo resultado es un vacío social, como si el espacio social, todo entrelazado, hubiera sido aplanado en un espacio hecho vacío. Deleuze sugiere que es más adecuado comprender el derrumbamiento de los muros constituidos por las instituciones cerradas como la generalización de lógicas que anteriormente funcionaron dentro de los dominios limitados en medio de la sociedad entera, y que ahora se difunden como un virus.

El espacio social no ha sido vaciado de las instituciones disciplinares; ha sido Ilenado

${ }^{8}$ G. Deleuze.»Las sociedades de control». Op.cit. 
mente deseable, las condiciones sociales necesarias por la existencia de la sociedad civil ya no existen.

La sociedad civil, como hemos visto, es central para un esquema de mando, o de gobierno -como dice Foucault- que se basa, por un lado, sobre la identidad de los ciudadanos y sobre los procesos de civilización y, de otro, sobre la organización del trabajo abstracto. Estos procesos, la educación, el adiestramiento o la disciplina, son concebidos de formas diferentes pero lo que tienen en común es el empeño activo con las fuerzas sociales (sea por medio de la mediación que de la producción) para ordenar las identidades sociales dentro del contexto de las instituciones. Lo que va desapareciendo, o más precisamente lo que va perdiendo importancia en la sociedad poscivil, son exactamente estas funciones de mediación o adiestramiento y las instituciones que les dieron una forma. (Negri, 2004)

Antes que disciplinar a los ciudadanos como una identidad social fija, el nuevo régimen social trata de controlar a los ciudadanos como una identidad cualquiera, o mejor como un subrogado de identidad infinitamente flexible. Movilidad, velocidad y flexibilidad son las cualidades que caracterizan este plan separado del mando. La máquina infinitamente programable, el ideal de los cibernéticos, nos da una vaga aproximación del esquema del nuevo paradigma del mando. Analizar las nuevas técnicas del control social es útil para aquellos aspectos que nos permiten agarrar las nuevas potencialidades de contestación y libertad listas a emerger dentro de este nuevo paradigma.

Para empezar a localizar estas nuevas potencialidades tenemos que ponernos a analizar las formas y la naturaleza del trabajo, o de las prácticas sociales creativas, en la sociedad contemporánea. Éste es uno de los modos en que podemos separarnos de la sociedad disciplinal y empezar a pensar líneas de poder y potencialidad en la nueva sociedad. Las prácticas sociales cambian indudablemente. El trabajo todavía es la fuente de la riqueza y la sociabilidad. Hasta en la sociedad de control, el trabajo todavía es esa "bestia salvaje" de la que tuvo miedo Hegel, siempre resistente a dejarse domesticar. Quizás su potencial es hoy mayor en la medida en que no es disciplinado por las instituciones de la sociedad civil como ocurrió en el anterior paradigma.

Podríamos concluir con Hardt (2002) que “La trama de la sociabilidad y las formas de la cooperación impresas en las prácticas sociales contemporáneas constituyen los gérmenes para un nuevo movimiento, con nuevas formas de contestación y nuevas concepciones de liberación. Esta comunidad alternativa de prácticas sociales (se puede probar a definirla autoorganización del trabajo concreto) será el desafío más potente al control de la sociedad civil y trazará, quizás, nuestra comunidad del futuro". 